\title{
Process Debottlenecking and Retrofit of Palm Oil Milling Process via Inoperability Input- Output Modelling
}

\author{
May May Tan ${ }^{1}$, Viknesh Andiappan ${ }^{2}$, and Yoke Kin $\mathrm{Wan}^{1 *}$ \\ ${ }^{1}$ School of Engineering, Taylor's University, Subang Jaya, Selangor, Malaysia. \\ ${ }^{2}$ School of Engineering and Physical Sciences, Heriot-Watt University Malaysia, No. 1 Jalan Venna \\ P5/2, Precinct 5, 62200 Putrajaya, Wilayah Persekutuan Putrajaya.
}

\begin{abstract}
In recent years, there has been an increase in crude palm oil (CPO) demand, resulting in palm oil mills (POMs) seizing the opportunity to increase $\mathrm{CPO}$ production to make more profits. A series of equipment are designed to operate in their optimum capacities in the current existing POMs. Some equipment may be limited by their maximum design capacities when there is a need to increase CPO production, resulting in process bottlenecks. In this research, a framework is developed to provide stepwise procedures on identifying bottlenecks and retrofitting a POM process to cater for the increase in production capacity. This framework adapts an algebraic approach known as Inoperability Input-Output Modelling (IIM). To illustrate the application of the framework, an industrial POM case study was solved using LINGO software in this work, by maximising its production capacity. Benefit-to-Cost Ratio (BCR) analysis was also performed to assess the economic feasibility. As results, the Screw Press was identified as the bottleneck. The retrofitting recommendation was to purchase an additional Screw Press to cater for the new throughput with BCR of 54.57. It was found the POM to be able to achieve the maximum targeted production capacity of $8,139.65 \mathrm{~kg} / \mathrm{hr}$ of CPO without any bottlenecks.
\end{abstract}

\section{Introduction}

Crude palm oil (CPO) is a commodity with large potential and is the most versatile vegetable oil, with the ability to be processed into a range of products with different characteristics [1]. The global demand for palm oil has been increasing at a rapid speed due to the increase in consumption all over the world. The reason for the vast economic growth of palm oil is that it is cheap to produce and has a production rate 10 times that of soy oil, which is its direct competitor [2]. In a POM, CPO is extracted from fresh fruit bunches

1 Corresponding author: YokeKin.Wan@taylors.edu.my 
(FFBs), which are harvested from oil palm trees. The process block diagram (PBD) of a typical POM is as depicted in Fig. 1.

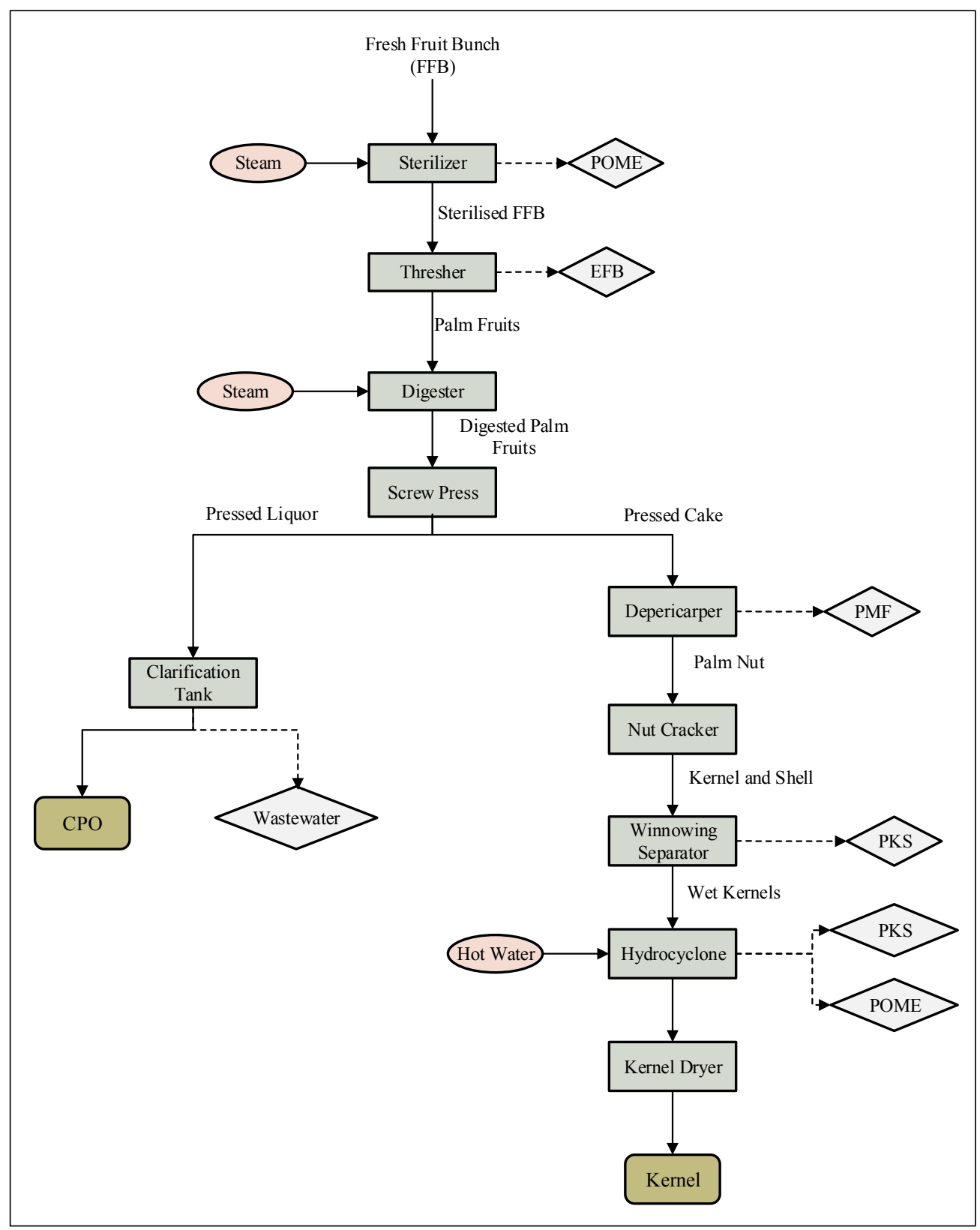

Fig. 1. Block flow diagram (BFD) of a typical POM process [3].

Each equipment in the POM has very specific functions and are designed to operate at their optimum capacities. When there is a need to increase CPO production, some of its 
equipment may be limited by their fixed design capacities, creating a process bottleneck. A process bottleneck is a situation whereby the available capacity of a process unit is insufficient to meet the increased production rates. The challenge becomes increasingly complex when a POM experiences a drop in equipment efficiency. To solve the mentioned challenges, production capacity of a POM can be increased by retrofitting a plant (e.g. building new production facilities, debottlenecking an existing plant or by designing a plant that meets the production capacity requirement prior to building it) [4]. However, since POM plants are very well-established, it is usually more economical to retrofit an existing POM by debottlenecking it [5].

Retrofitting refers to a procedure to implement modifications to an existing process or system that may improve its energy efficiency, decrease its energy demand, increase its capacity and etc [6]. Several research works have been presented in the area of retrofitting, proving the importance of increasing the productivity of a process to fit increase in demand of a product $[7,8]$. In literature, retrofitting and debottlenecking approaches have been proposed in areas including using computer-aided simulation tools, mathematical modelling and programming tools, and systematic frameworks [4, 8-12]. Previous works related to process retrofitting and debottlenecking were focused on the industries such as heat exchanger networks, pharmaceutical, biorefinery and bioenergy $[4,9,11,13]$. However, there is limited work done on a retrofit and debottlenecking framework of a POM to cater for increased CPO production. At present, work has only been focused on palm oil-based biomass utilisation in a biorefinery and biomass tri-generation system from a palm oil mill (POM), but not the operations of the POM itself $[4,13]$.

Hence, this research presents a debottlenecking framework, which serves as a stepwise guideline and decision-making tool for engineers to identify bottlenecks and debottleneck the process when there is a desire to increase production capacity. To illustrate the application of the framework, an existing POM was solved in this work, by maximising its production capacity. The identification of bottlenecks was carried out by first developing the mathematical model of the process using an algebraic approach, known as Inoperability Input-output Modelling (IIM) adapted from the work of Kasivisvanathan et al. [4]. IIM assumes that each equipment is a 'blackbox', meaning that the operating conditions of the equipment are not considered. The model was then solved using a commercial optimisation tool, known as LINGO v17.0 [14]. The results of the model were analysed to determine the equipment which have become process bottlenecks. Upon identifying the bottlenecks in the process, the framework entails the procedures on retrofitting a POM process to cater for the increased production capacity. Following this, once the POM was free from bottlenecks, benefit-to-cost ratio (BCR) was performed on the debottlenecking methods to analyse the economic feasibility. Based on the economic performance, the decision to approve the debottlenecking solution is then made.

With this framework, process engineers are able to analyse, and make informed decisions on the debottlenecking a POM process in a systematic manner. The challenge of process bottlenecking can surface in any process. Hence, the purpose of this approach is not limited to a POM production process, it can also be applied to any process that may face potential bottlenecks. 


\section{Research Methodology}

\subsection{Debottlenecking Framework}

The debottlenecking framework methodology in Figure 2 essentially acts as a step-by-step guide and a decision-making tool for engineers to debottleneck a process. Section 2.2 to 2.3 explains the framework steps in detail.

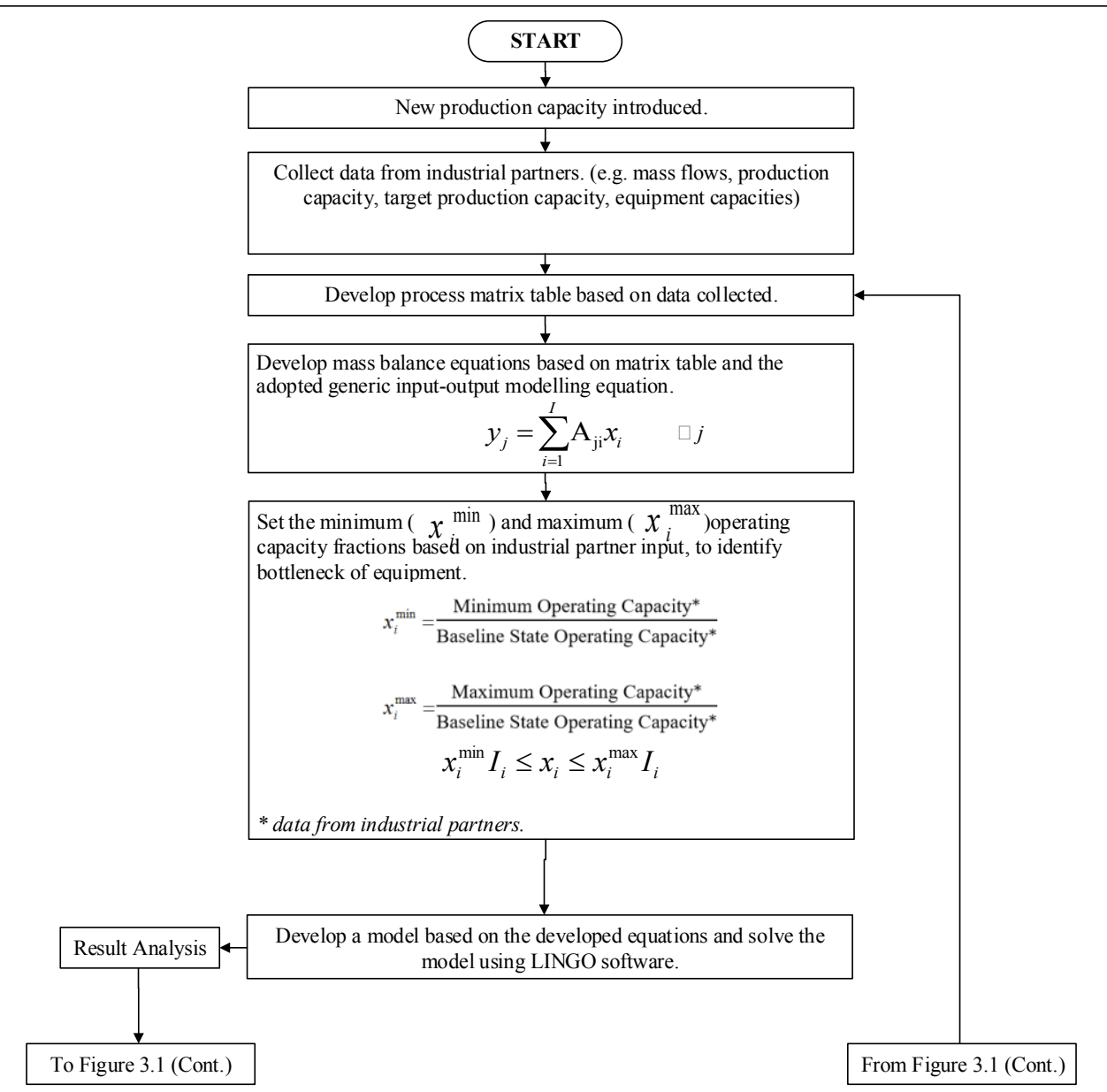

Fig. 2. Debottlenecking framework methodology. 


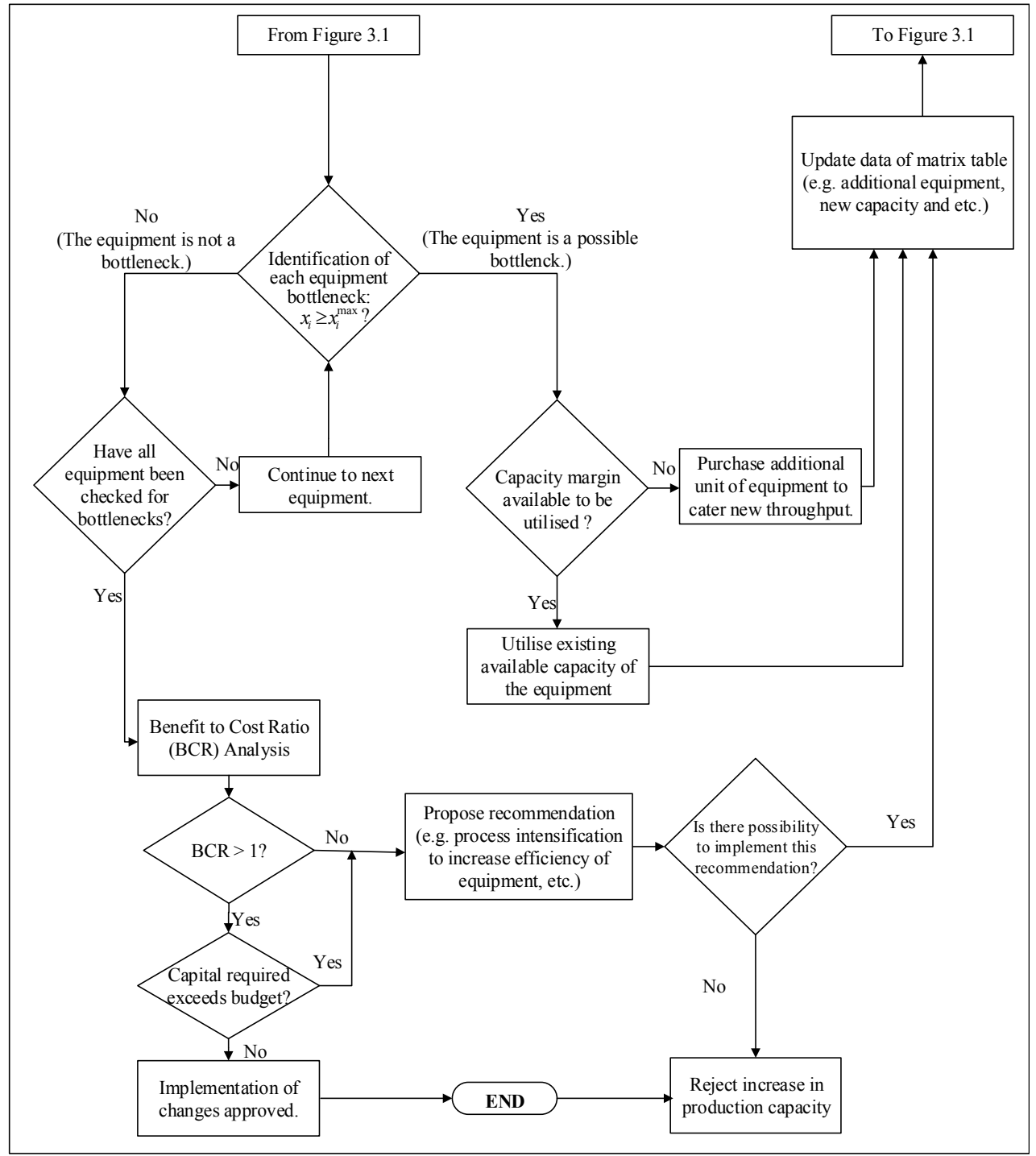

Fig. 3. Debottlenecking framework methodology (Cont.).

As shown in Figure 2, when the need to increase production capacity arises, the first task in the framework is to collect information of the process and equipment from industrial partners for study and analysis as shown in Table 1. For any confidential data that was unavailable, assumptions can be made based on similar, heuristic values or theoretical calculations. 
Table 1. Data required for process and specification required for process unit.

\begin{tabular}{|c|c|}
\hline Process & Process Unit \\
\hline Target capacity for increased production & Design capacities \\
\hline Number of equipment used of each process step & Minimum and maximum operating capacity \\
\hline Process flow, Mass flow & Capital cost of equipment \\
\hline Production capacity during normal operation & Utility consumption \\
\hline
\end{tabular}

Moving down the framework to the next task, a process matrix table needs to be constructed. A general example of a matrix table is shown in Table 2. It shows the mass flows of components, $j(\mathrm{j}=1,2,3 \ldots \mathrm{J})$, through each process unit, $i(i=1,2,3 \ldots \mathrm{I})$, for baseline state operation. In this work, the baseline state operation is referred to the normal existing operating capacity of the plant, before there is an increase in production capacity. Next, mathematical model needs to be formulated based on the matrix table shown in Table 2 . The detailed explanation is presented in Section 2.1.

Table 1. General example of a process matrix table.

\begin{tabular}{|c|ccccc|}
\hline Component, $y_{j}$ & $\mathrm{x}_{1}$ & $\mathrm{x}_{3}$ & $\ldots$ & $\mathrm{x}_{\mathrm{i}}$ \\
\hline $\mathrm{y}_{1}$ & $\mathrm{~A}_{1,1}$ & $\mathrm{~A}_{1,2}$ & $\mathrm{~A}_{1,3}$ & $\ldots$ & $\mathrm{A}_{1, \mathrm{j}}$ \\
$\mathrm{y}_{2}$ & $\mathrm{~A}_{2,1}$ & $\mathrm{~A}_{2,2}$ & $\mathrm{~A}_{2,3}$ & $\ldots$ & $\mathrm{A}_{2, \mathrm{j}}$ \\
$\mathrm{y}_{3}$ & $\mathrm{~A}_{3,1}$ & $\mathrm{~A}_{3,2}$ & $\mathrm{~A}_{3,3}$ & $\ldots$ & $\mathrm{A}_{3, \mathrm{j}}$ \\
$\ldots$ & $\ldots$ & $\ldots$ & $\ldots$ & $\ldots$ & $\ldots$ \\
$\mathrm{y}_{\mathrm{j}}$ & $\mathrm{A}_{\mathrm{i}, 1}$ & $\mathrm{~A}_{\mathrm{i}, 2}$ & $\mathrm{~A}_{\mathrm{i}, 3}$ & $\ldots$ & $\mathrm{A}_{\mathrm{i}, \mathrm{j}}$ \\
\hline
\end{tabular}

\subsection{Formulation of Model}

Based on the matrix table in Table 2, the process is then modelled using an algebraic approach known as input-output modelling. A general expression for input-output modelling adapted from the work of Kasivisvanathan et al.[4] is shown in Eq. (1),

$$
y_{j}=\sum_{i=1}^{I} \mathrm{~A}_{\mathrm{ji}} x_{i} \quad \forall j
$$

where $y_{j}$ is the net flowrate of a given component, which can be an intermediate or a product. It is noted that $y_{j}$ is denoted by a negative sign for inputs, a positive sign for outputs and is equal to zero for all intermediates. $i(i=1,2, \ldots, \mathrm{I})$ represents a process unit 
index, $j(j=1,2, \ldots, \mathrm{J})$ represents the type of component. $\mathrm{A}_{\mathrm{ji}}$ showed in the matrix table represents the input and output mass flows to and from a certain process unit $i$. Meanwhile, $x_{i}$ is an input-output variable of the equation, known as the operating capacity fraction for a process unit (where baseline state is denoted by 1).

Based on input-output modelling, the net output of the intermediate products in the process are fixed to zero as shown in Eq. (2) below.

$$
y_{j}=0
$$

This is to ensure that all the intermediate products will be completely converted to produce the final product at the capacity that the plant is designed for [4]. Other than the formulation of the modelling equations, the constrains required to solve the model (i.e. minimum and maximum operating capacity fractions, $\mathrm{x}_{i}^{\min }$ and $\mathrm{x}_{i}^{\max }$ ) are formulated as well, which has been further discussed in Section 2.3.

\subsection{Set the Minimum and Maximum Operating Capacity Fractions}

The next task in the framework presented in Figure 2 is to set the minimum and maximum operating capacity fractions, $\mathrm{x}_{i}^{\min }$ and $\mathrm{x}_{i}^{\max }$, of each process unit. As seen in Eq. (1), the input-output variable, $x_{i}$, is the operating capacity fraction of a particular process unit. Each process unit has a minimum and maximum limit of operating capacity fraction whereby it is safe to operate. This is required to limit the model, in order to properly identify bottlenecks. $\mathrm{x}_{i}^{\min }$ and $\mathrm{x}_{i}^{\max }$ of each process unit has to be determined using Eqs. (3) and (4) based on the information provided by industrial partners.

$$
\begin{aligned}
\mathrm{X}_{i}^{\min } & =\frac{\text { Minimum Operating Capacity* }}{\text { Baseline State Operating Capacity* }} \\
\mathrm{X}_{i}^{\max } & =\frac{\text { Maximum Operating Capacity* }}{\text { Baseline State Operating Capacity* }}
\end{aligned}
$$

\section{* provided by industrial partners.}

The formulation of the range of operating capacity fraction that is to be modelled in LINGO is as shown in Eq. (5).

$$
\mathrm{x}_{i}^{\min } I_{i} \leq x_{i} \leq \mathrm{x}_{i}^{\max } I_{i} \quad \forall i
$$

where $x_{i}$ is the operating capacity fraction of process unit $i(i=1,2,3 \ldots, I)$ and $I_{i}$ is a binary number $\left(I_{i}=0\right.$ or $\left.I_{i}=1\right)$. For better understanding, during baseline state operation, the operating capacity fraction of an equipment, $x_{i}$, is equal to 1 . When a new production capacity is introduced, $x_{i}$ might move above or below 1 . The model is able to compute the value of $x_{i}$ of the process unit. If it is running below the normal capacity, $x_{i}$ is less than 1 , 
and is not a possible bottleneck; if it is running over the normal capacity, $x_{i}$ is larger than 1 , then it may be at risk of being a bottleneck. If $x_{i}$ is equal or larger than $\mathrm{x}_{i}^{\max }$, then the equipment is most definitely a bottleneck.

Moving down in the framework (Figure 2), the model could be solved using a commercial optimisation software known as LINGO and data below is extracted from the results:

1. The operating capacity fraction, $x_{i}$, of all process units,

2. The production capacity of the plant (i.e. amount of product produced).

Following the solved model, Section 2.3 entails the analysis of the result obtained from the model to identify of bottlenecks in the process.

\subsection{Identification of Bottlenecks}

After the model is solved, the process is checked for any bottlenecks which may have occurred by analysing the results of the model. Beginning from the 'Result Analysis' box onwards in Figure 2, the analysis will be limited to only one process unit before moving to the next unit. The loop continues until all process units have been checked for bottlenecks. For example, if the equipment is a bottleneck, further analysis is carried out to determine if there is existing capacity margin available to be utilised; this will be discussed in Section 2.5. If the equipment is not a bottleneck, then the next equipment will be checked for bottlenecks. This is done until all equipment have been checked for bottlenecks, then the economic analysis is carried out to assess the feasibility of the debottlenecking method proposed as discussed in Section 2.6.

\subsection{Debottlenecking}

From Section 2.4, if the particular process unit is a possible bottleneck, the framework will lead to the next diamond box shown in Figure 2, to be checked for additional capacity available. Some process steps may have more than one process unit operating in parallel; meaning that if one unit is a bottleneck, there may be capacity available in another unit, allowing for the utilisation of available existing capacity in the other unit. This can be checked by first calculating the capacity required for the process step and the available capacity for the process step, using Eq. (6) and (7) which is obtained by rearranging Eq. (3) and (4).

$$
\text { Capacity Required for Process }=x_{i} \times \text { Baseline State Capacity }
$$

$$
\text { Available Capacity }=\text { Capacity of Equipment } \times \text { Number of Equipment }
$$

Following this, based on Figure 2, if there is margin available for adjustments, the bottleneck can be removed by utilising the available capacity in the other equipment which is operating in parallel. If there is no margin available, the debottlenecking solution is to purchase additional unit of equipment. Once the debottlenecking method for a particular process unit is decided, the data in the matrix table needs to be updated and the formulations in the model are then updated accordingly. The entire process is then reanalysed for bottlenecks again. For example, if an additional unit of equipment is 
purchased, the operating capacity fraction, $x_{i}$, for that particular equipment is introduced into the matrix table, then the steps described from Section 2.2 onwards are carried out again. This is done until the entire network is free from any other equipment bottlenecks. Once there are no more bottlenecks and all equipment have been checked, the economic feasibility of the debottlenecking solution is assessed in Section 2.6.

\subsection{Benefit-to-Cost Ratio (BCR) Analysis}

Benefit-to-cost ratio (BCR) analysis of the proposed debottlenecking solutions is performed to assess the feasibility of the modifications. BCR is to determine the ratio of profits gained by implementing the recommendation to the initial capital investment of implementing the recommendation. BCR can be calculated using Eq. (8).

$$
B C R=\frac{\mathrm{C}_{\mathrm{j}}\left(\Delta y_{j}\right)}{C_{e q}}
$$

where $j$ is the valuable product of the process which brings in profits, $\mathrm{C}_{\mathrm{j}}$ is the price of component $j$ and $\Delta y_{j}$ is the increased flow rates of component $j$ after debottlenecking is performed. $\mathrm{C}_{\mathrm{eq}}$ is the annualised capital cost and annual operating costs of the equipment purchased to solve the process bottleneck, calculated using Eq. (9).

$$
C_{e q}=\sum_{i=1}^{I}\left(\mathrm{C}_{\mathrm{i}} \mathrm{x}_{i}^{\max }+\mathrm{C}_{\mathrm{AOC}, \mathrm{i}}\right)
$$

where $i\left(i=1,2,3\right.$ or...I) refers to the process units that have been added to the process, $\mathrm{C}_{\mathrm{i}}$ is the annualised capital cost of the process unit at maximum operating capacity fraction, $\mathrm{x}_{i}^{\max }$ and $\mathrm{C}_{\mathrm{AOC}, \mathrm{i}}$ is the annual operating cost of the process unit.

Referring to the framework in Figure 2, the BCR is less than 1, this means that the cost outweighs the benefits. In this case, the process bottlenecks would have to be re-assessed and overcome using different methods (e.g. purchase smaller equipment or process intensification to increase yield of a process) if applicable. On the contrary, when BCR is more than 1, this shows that the benefits of the modification outweigh the costs. In line with $\mathrm{BCR}$, a secondary evaluation is done on the allocated budget. If the investment on the debottlenecking solution falls below the budget, the decision is made to approve the solution. However, if both BCR and/or budget constraints are not satisfied (i.e. BCR $<1$ and/or Capital Cost $>$ Allocated Budget), new debottlenecking solutions will have to be proposed and the process will be reanalysed for bottlenecks. For example, a possible recommendation to reduce the initial capital investment is to reduce the maximum operating capacity of the equipment. The plant is then to be re-analysed to determine if these modifications would bring about other bottlenecks. The cycle continues until it reaches the end stage of the framework in Figure 2. In the case where all proposed recommendations have to be rejected due to not achieving the desired results for economic analysis, the entire project will have to be abandoned. This means that the plant is not suited for increase in production capacity or the budget provided is insufficient. To 
demonstrate the application of the developed framework (Figure 2), the bottleneck identification and debottlenecking of a palm oil mill (POM) case study is presented in Section 3.

\section{Palm Oil Mill (POM) Case Study}

Figure 3 illustrates a process block diagram (PBD) of an existing and operating palm oil mill (POM) case study that will be used to demonstrate the debottlenecking framework steps described in Section 2. The POM owner is interested in maximising the crude palm oil (CPO) production capacity of the existing POM with a budget allocation of US\$ 500,000. This increase of CPO production may cause some of the equipment in Figure 3 to reach their maximum capacities and result in process bottlenecks. In this case, the proposed framework serves as a stepwise guideline and decision-making tool to analyse the plant for increased production and to debottleneck accordingly. Based on the framework (Figure 2), the data of the POM were first collected from industrial partners. Some information of the equipment specifications of the POM at baseline state are shown in Table 3. Table 4 is the process matrix table, which shows the capacities of the equipment in the POM at baseline state, also obtained from industrial partners. In Table 4, the negative values are the inputs into an equipment and the positive values are the outputs of an equipment.

Table 2. Current specifications of existing palm oil mill (POM) at baseline state.

\begin{aligned} & Fresh fruit bunches (FFB) Consumed $(\mathrm{kg} / \mathrm{hr}) 30,000 \\ &$ CPO Production Capacity $(\mathrm{kg} / \mathrm{hr}) 7611.42 \\ &$ Steam Consumption $(\mathrm{kg} / \mathrm{hr}) 15435.85 \\ &$ Electricity Consumption $(\mathrm{kWh}) 419.8 \\ &$\hline\end{aligned}

Table 3. Equipment specifications in Palm Oil Mill (POM).

\begin{tabular}{|c|c|c|c|c|c|}
\hline Equipment & Unit & $\begin{array}{l}\text { Maximum } \\
\text { Capacity }\end{array}$ & $\begin{array}{l}\text { Minimum } \\
\text { Capacity }\end{array}$ & $\begin{array}{c}\text { Steam } \\
\text { Consumption } \\
(\mathrm{kg} / \mathrm{kg} \text { FFB })\end{array}$ & $\begin{array}{l}\text { Electricity } \\
\text { (kWh/unit) }\end{array}$ \\
\hline Steriliser & kg FFB/unit & 20000 & 8,000 & 0.25 & 30 \\
\hline $\begin{array}{c}\text { Thresher } \\
\text { Steam }\end{array}$ & $\mathrm{kg} \mathrm{SFB/unit}$ & 50,000 & 20,000 & - & 28 \\
\hline $\begin{array}{l}\text { Injection } \\
\text { Digester }\end{array}$ & kg SFB/unit & 12,500 & 5,000 & 0.13 & 18 \\
\hline Screw Press & kg DF/unit & 20,000 & 8,000 & - & 45 \\
\hline $\begin{array}{l}2 \text {-Phase } \\
\text { Decanter }\end{array}$ & kg PL/unit & 10,000 & 4,000 & - & 40 \\
\hline Depericarper & kg PC/unit & 5,000 & 2,000 & - & 57.3 \\
\hline Nut Cracker & kg PF/unit & 8,000 & 3,200 & - & 26.4 \\
\hline $\begin{array}{c}\text { 4-stage } \\
\text { Winnowing } \\
\text { Column }\end{array}$ & $\begin{array}{l}\mathrm{kg} \text { cracked } \\
\text { mixture/unit }\end{array}$ & 15,000 & 3,000 & - & 20 \\
\hline Hydrocyclone & $\begin{array}{l}\mathrm{kg} \text { cracked } \\
\text { mixture/unit }\end{array}$ & 5,000 & 2,000 & $\begin{array}{c}\text { Water: } 1.5 \\
\mathrm{~kg} / \mathrm{kg} \text { cracked } \\
\text { nut }\end{array}$ & 30 \\
\hline Kernel Dryer & $\mathrm{kg} \mathrm{WK/unit}$ & $\begin{array}{c}5,000 \mathrm{~kg} \text { wet } \\
\text { kernet/unit }\end{array}$ & 1,000 & - & 37.1 \\
\hline
\end{tabular}




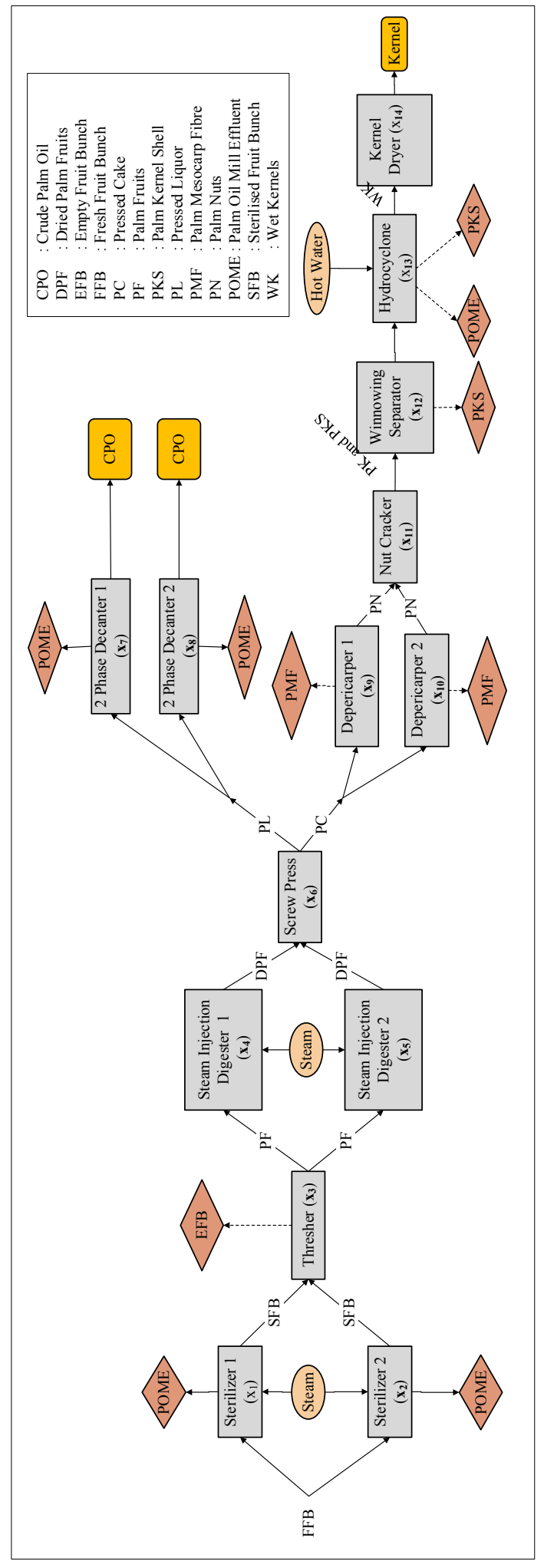

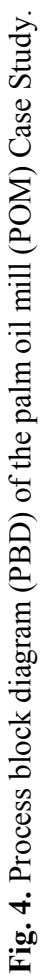



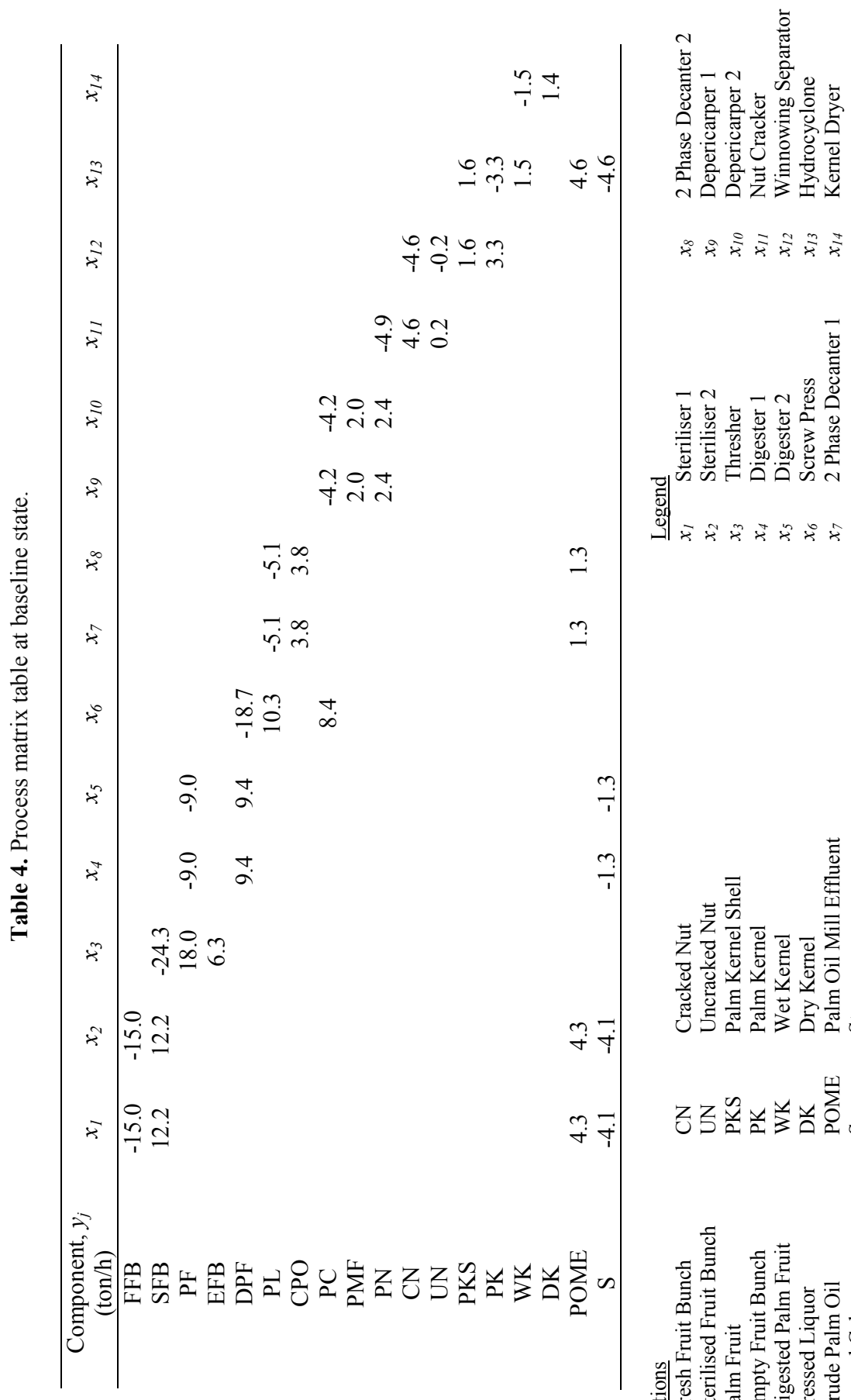

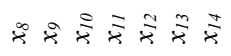
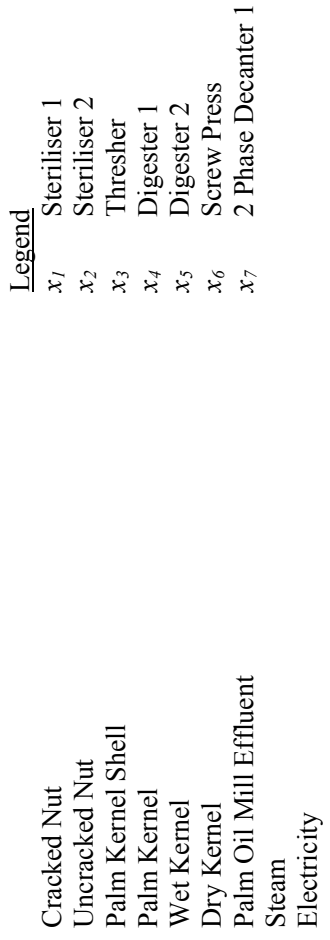

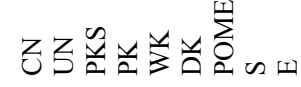

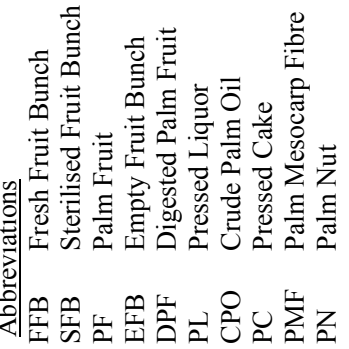


The next step in the framework is to formulate the input-output model of the POM based on Eq. (1), using the mass flow values in Table 4. Based on Eq. (2), the intermediates of the process are set to zero. Next, the minimum and maximum operating capacity fractions were calculated using based Eq. (3) and (4), and the information in Table 3. The constrains were formulated using Eq. (5). After the completion of these steps, the model is ready to be solved using LINGO v17.0. The results of the model are presented and discussed Section 3.1 .

\subsection{Results and Discussion}

In this case study, the crude palm oil (CPO) production capacity was maximised and the palm oil mill (POM) was analysed for bottlenecks. The POM model is solved for the objective function to maximise the production capacity of CPO shown in Eq. (10).

$$
\max C P O
$$

Upon modelling and solving the POM case study, the results showed that the existing POM was able to achieve a maximum CPO production capacity of $8139.65 \mathrm{~kg} / \mathrm{hr}$ and the results are tabulated in the fifth column of Table 6 . Based on the framework, the operating capacity fractions of each equipment upon introducing the increased capacity (in the fifth column of Table 4) is to be compared with the existing maximum operating capacity fraction of the equipment (in the fourth column of Table 4).

Table 5. Identification of possible bottlenecks.

\begin{tabular}{cccccc}
\hline Equipment & $\begin{array}{c}\text { Input- } \\
\text { Output } \\
\text { Variable, } \\
x_{i}\end{array}$ & $\begin{array}{c}\text { Minimum } \\
\text { Operating } \\
\text { Capacity, } \\
\mathrm{X}_{i}^{\min }\end{array}$ & $\begin{array}{c}\text { Maximum } \\
\text { Operating } \\
\text { Capacity, } \\
\mathrm{X}_{i}^{\max }\end{array}$ & $\begin{array}{c}\text { Operating } \\
\text { Capacity } \\
\text { Fraction to } \\
\text { Maximise CPO, } \\
x_{i}\end{array}$ & $\begin{array}{c}\text { Possible } \\
\text { bottleneck }\end{array}$ \\
\hline Steriliser 1 & $x_{1}$ & 0.5333 & 1.3333 & 1.3330 & YES \\
Steriliser 2 & $x_{2}$ & 0.5333 & 1.3333 & 0.8058 & NO \\
Thresher & $x_{3}$ & 0.8230 & 2.0576 & 1.0694 & NO \\
Digester 1 & $x_{4}$ & 0.5561 & 1.3903 & 0.7485 & NO \\
Digester 2 & $x_{5}$ & 0.5561 & 1.3903 & 1.3903 & YES \\
Screw Press & $x_{6}$ & 0.4278 & 1.0694 & 1.0694 & YES \\
Decanter 1 & $x_{7}$ & 0.7778 & 1.9444 & 0.7778 & NO \\
Decanter 2 & $x_{8}$ & 0.7778 & 1.9444 & 1.3610 & NO \\
Depericarper 1 & $x_{9}$ & 0.4753 & 1.1883 & 0.9505 & NO \\
Depericarper 2 & $x_{10}$ & 0.4753 & 1.1883 & 1.1883 & YES \\
Nut Cracker & $x_{11}$ & 0.6556 & 1.6390 & 1.0269 & NO \\
Winnowing & $x_{12}$ & 0.6146 & 3.0731 & 1.0269 & NO \\
Separator & $x_{13}$ & 0.6146 & 1.5369 & 1.0269 & NO \\
Hydrocyclonne & $x_{14}$ & 0.6884 & 3.4422 & 1.0269 & NO \\
Kernel Dryer & & & & &
\end{tabular}


The comparisons suggested that the possible equipment bottlenecks were the Steriliser 1, Digester 2, Screw Press and Depericarper 2. These are the processes that may be at risk of becoming bottlenecks, should there be a further increase in capacity. This is probably because the Digester and any process relating to palm nut (PN) processing (i.e. Depericarper) had smaller operating capacities compared to other equipment (i.e. Capacity of the Digester is $12,500 \mathrm{~kg}$ palm fruit/hr for one unit and capacity of Depericarper is 5000 $\mathrm{kg}$ pressed cake/hr for one unit).

Moving down the next diamond box in the framework, the possible bottlenecks identified were then checked if there was available existing margin available to be utilised. This means that the particular process step may have more than one of the same equipment running in parallel, which has excess capacity that can be utilised (i.e. from Figure 3, the Steriliser, Digester, Depericarper and 2-phase Decanter). The calculations were made using Eq. (6) and (7). The results tabulated in Table 7 suggested that the all the possible bottlenecks had available existing capacity to be utilised, except for the Screw Press, which was approaching its maximum available capacity. The conclusion made from this step was that the Steriliser, Digester and Depericarper had available capacity margin to be utilised, because hese processes have two process units which operate in parallel. Hence, when one is at its maximum capacity, the other still had excess capacity to be utilised. However, the Screw Pressing process had only one equipment in the existing POM, leaving no capacity available to be utilised. Therefore, the bottleneck identified and validated for the case study was the Screw Press.

Table 6. Checking for available existing capacity.

\begin{tabular}{cccc}
\hline Possible Bottlenecks & $\begin{array}{c}\text { Capacity Required } \\
(\mathrm{kg} / \mathrm{hr})\end{array}$ & $\begin{array}{c}\text { Available Capacity } \\
(\mathrm{kg} / \mathrm{hr})\end{array}$ & $\begin{array}{c}\text { Available Existing } \\
\text { Capacity Margin to } \\
\text { be Utilised? }\end{array}$ \\
\hline Steriliser 1 & $32,081.99$ & $40,000.00$ & YES \\
Digester 2 & $19,229.95$ & $25,000.00$ & YES \\
Screw Press & $19,999.15$ & $20,000.00$ & Approaching Max \\
Depericarper 2 & $8,999.62$ & $10,000.00$ & YES \\
\hline
\end{tabular}

Based on the framework (Figure 2), the subsequent step was to debottleneck the Screw Press. In this research, all equipment was assumed to be a 'blackbox', meaning that operating conditions and efficiencies are not taken into consideration and are assumed to be at optimum. However, in reality this may not be the case. Each equipment has its own range of operating conditions at which it has the best performance. For example, a Screw Press may have an optimum operating capacity fraction, $x_{6}$, between 0.8 to 0.9 , where it may be able to have a higher efficiency. However, since this research is conducted with the assumption of a 'black box', this optimum range is not taken into consideration. Hence, based on the framework (Figure 2), the debottlenecking method selected was by purchasing an additional Screw Press. to cater for the new capacity. Following the decision of the debottlenecking method, the next step is to update the process matrix table, equipment constraints and mathematical model accordingly based on the modifications made. The modifications made (i.e. purchase an additional Screw Press) will allow the POM to have a new maximum CPO capacity. However, since a comparison would like to be made between existing POM and debottlenecked POM, the constraint in Eq. (11) below, has to be defined in the model. 


$$
C P O=8139.65
$$

This was done because based on the previous LINGO results mentioned, the maximum CPO capacity of the existing plant was found to be $8139.64 \mathrm{~kg} / \mathrm{hr}$. Hence, by introducing Eq. (11) to the model, a comparison can be made to check if the bottlenecks that occurred from the said capacity have been removed. The results are tabulated in Tables 8 to 11 . Table 8 shows that Screw Press 1 is at its maximum capacity and is a possible bottleneck. However, the Screw Press 2 that was just added is at zero capacity. Hence, there is existing margin available to be utilised for the Screw Press process, as shown in Table 9. With the additional Screw Press 2, the Screw Pressing process is now able to handle a larger throughput, allowing the plant to achieve the maximised CPO capacity without any bottlenecks.

Table 7. Identification of bottlenecks after debottlenecking.

\begin{tabular}{cccccc}
\hline & $\begin{array}{c}\text { Input- } \\
\text { Eutput } \\
\text { Eariable, }\end{array}$ & $\begin{array}{c}\text { Minimum } \\
\text { Operating } \\
\text { Capacity, }\end{array}$ & $\begin{array}{c}\text { Maximum } \\
\text { Operating } \\
\text { Capacity, }\end{array}$ & $\begin{array}{c}\text { Operating Capacity } \\
\text { Fraction to } \\
\text { Maximise CPO, }\end{array}$ & $\begin{array}{c}\text { Possible } \\
\text { bottleneck } \\
\end{array}$ \\
$x_{i}$ & $x_{i}^{\min }$ & $x_{i}^{\max }$ & $x_{i}$ & $?$ \\
\hline Screw Press 1 & $x_{6}$ & 0.8556 & 2.1389 & 2.1388 & YES \\
Screw Press 2 & $x_{6 a}$ & 0.8556 & 2.1389 & 0.0000 & NO \\
\hline
\end{tabular}

Table 8. Check for capacity margin available for adjustment after debottlenecking.

\begin{tabular}{cccc}
\hline Bottlenecks & $\begin{array}{c}\text { Capacity Required } \\
(\mathrm{kg} / \mathrm{hr})\end{array}$ & $\begin{array}{c}\text { Available Capacity } \\
(\mathrm{kg} / \mathrm{hr})\end{array}$ & $\begin{array}{c}\text { Available margin for } \\
\text { adjustment? }\end{array}$ \\
\hline Screw Press & 19999.15 & 40000.00 & YES \\
\hline
\end{tabular}

According to Table 10, upon debottlenecking the existing POM for maximised CPO production capacity, it is now able to produce $8139.65 \mathrm{~kg} \mathrm{CPO} / \mathrm{hr}$, by consuming 32,082.00 $\mathrm{kg} \mathrm{FFB} / \mathrm{hr}, 16,507.08 \mathrm{~kg}$ steam $/ \mathrm{hr}$ and $522.1 \mathrm{kWh}$ of electricity. By comparing the CPO production capacity to the baseline state shown in Table 3 (i.e. $7611.42 \mathrm{~kg} \mathrm{CPO} / \mathrm{hr}$ ), the CPO capacity of the debottlenecked plant is has increased by $7 \%$. With the increase in production, the amount of raw material (i.e. fresh fruit bunch (FFB) and steam) consumed has also increased by 7\%. A trend is observed in the interactions of the mass flows, whereby an increase in production of CPO leads to the same percentage of increase in consumptions of raw material and utilities required in the process. This is because the process units in the POM are interconnected by a linear programming model. This high interdependency among individual process units results in disruption of the entire system when there are any changes made (i.e. increase production capacity of CPO). The electricity consumption was found to be the same because the additional Screw Press added into the process was not being utilised, as shown in Table 8, where the operating capacity fraction was equal to zero.

Table 9. Production capacity and process requirements after debottlenecking.

\begin{tabular}{cc}
\hline New CPO Production Capacity $(\mathrm{kg} / \mathrm{hr})$ & 8139.65 \\
New FFB Capacity $(\mathrm{kg} / \mathrm{hr})$ & $32,082.00$ \\
Steam Consumption $(\mathrm{kg} / \mathrm{hr})$ & 16507.08 \\
\hline
\end{tabular}


Based on the framework (Figure 2), after the entire process is free from bottlenecks, the next step is to perform benefit-to-cost ratio analysis (BCR). The BCR was calculated using Eq. (8) and Eq. (9). The economic parameters used, information on the capital cost and annual operating cost of the equipment, along with the calculated values for BCR can be found in Table 9. From Table 9, by purchasing an additional Screw Press, the BCR obtained for the case study was 54.57 , which is a lot more than 1 . This shows that the additional income gained from increased CPO production far outweighs the cost required to purchase an additional Screw Press. This also shows that one process bottleneck could lead to a big loss in potential revenue that could be earned. Other than that, the BCR could be very high because there was only one equipment bottleneck. After debottlenecking, the POM now has a production capacity $7 \%$ higher than the baseline. If for example, the POM owners would like to increase capacity by $50 \%$, a lot more equipment would become bottlenecks and required to be debottlenecked. Different equipment have different costs, some have higher costs than others. These differences would reflect in the BCR results. Since in this case study, there is only one bottleneck involved, the BCR yields a value much larger than 1 .

The following step in the framework was to verify if the cost to carry out the project exceeds the allocated budget of the project. In line with BCR, the initial capital investment of the Screw Press (i.e. US\$ 100,000) is lesser than the budget allocated of US\$500,000. Therefore, the debottlenecking solution can be justified economically and can be approved for construction.

Table 10. Benefit-to-cost ratio analysis for case study.

\begin{tabular}{|c|c|}
\hline Total Operating Hours (hrs/yr) & 6000 \\
\hline Additional CPO from Increased Capacity, $\Delta y_{C P O}(\mathrm{~kg} / \mathrm{hr})$ & 528.23 \\
\hline$(\mathrm{kg} / \mathrm{yr})$ & $3,169,380.00$ \\
\hline Selling Price of $\mathrm{CPO}, \mathrm{C}_{\mathrm{CPO}}(\mathrm{US} \$ \mathrm{~kg})$ & 0.6565 \\
\hline $\mathrm{C}_{\mathrm{CPO}} \Delta y_{C P O}(\mathrm{US} \$ / \mathrm{yr})$ & $2,080,697.97$ \\
\hline Annualising Factor (/yr) & 0.1315 \\
\hline Capital Cost of Screw Press (US\$) & $100,000.00$ \\
\hline Annualised Capital Cost of Screw Press, $C_{6 a}$ (US\$/yr) & $13,150.00$ \\
\hline Maximum Operating Capacity Fraction of Screw Press, $x_{6 a}^{\max }$ & 2.1389 \\
\hline $\mathrm{C}_{6 \mathrm{a}} x_{6 a}^{\max }(\mathrm{US} \$ / \mathrm{yr})$ & $28,126.42$ \\
\hline Annual Operating Cost of Screw Press (US\$/yr) & 10,000 \\
\hline Cost of Additional Equipment, $C_{\text {eq }}$ (US\$/yr) & $38,126.42$ \\
\hline BCR & 54.57(ACCEPTABLE) \\
\hline
\end{tabular}

\section{Conclusion}

This research work presents a framework on identifying bottlenecks and debottlenecking in a palm oil milling (POM) process in the case where production capacity of crude palm oil (CPO) is required to increase. To identify the bottlenecks, an algebraic approach known as input-output modelling is adapted to first formulate the modelling equations of the process. The model was then solved in an optimisation tool, known as LINGO, to identify the 
bottlenecks. In addition to identifying the bottlenecks, the framework then proposes debottlenecking methods to free the process from bottlenecks. Benefit-to-cost ratio (BCR) analysis was performed on the debottlenecking methods to analyse its economic feasibility. To illustrate the developed framework, an existing POM was presented, given the objective to maximise $\mathrm{CPO}$ production capacity. It was found that the equipment at high risk of becoming possible bottlenecks when capacity increases were the Steriliser, Digester, Screw Press and Depericarper. The equipment which reached its maximum design capacity was identified as the Screw Press. The debottlenecking solution selected was to purchase an additional Screw Press to cater for the increase in capacity. After debottlenecking, the plant was able to produce an additional $528.23 \mathrm{~kg} \mathrm{CPO} / \mathrm{hr}$, which was a $7 \%$ increase from the baseline state. The BCR was found to be 54.57. This validates that the benefits of purchasing the additional Screw Press far outweighs the cost.

\section{References}

[1] Green Palm, "Why is Palm Oil Important?," 2015. [Online]. Available: http://greenpalm.org/about-palm-oil/why-is-palm-oil-important. [Accessed: 24-Oct2017].

[2] J. Mark, "What's Fueling the Demand for the Palm Oil Destroying the Rainforests of Indonesia?," 2013. [Online]. Available: http://www.earthisland.org/journal/index.php/elist/eListRead/whats_fueling_the_de mand_for_the_palm_oil_destroying_the_rainforests_of_ind/. [Accessed: 11-Jun2017].

[3] E. Lau, Y. Man, and A. Baharum, “A Qualitative Approach of Identifying Major Cost Influencing Factors in Palm Oil Mills and the Relations towards Production Cost of Crude Palm Oil," Am. J. Appl. Sci., 8, no. 5, pp. 441-446, (2011)

[4] H. Kasivisvanathan, R. R. Tan, D. K. S. Ng, M. K. Abdul Aziz, and D. C. Y. Foo, "Heuristic framework for the debottlenecking of a palm oil-based integrated biorefinery," Chem. Eng. Res. Des., (2014)

[5] Malaysia Palm Oil Council, "The Oil Palm Tree." [Online]. Available: http://www.mpoc.org.my/The_Oil_Palm_Tree.aspx. [Accessed: 17-Jun-2017].

[6] T. Pinto-Varela, A. Barbosa-Póvoa, and A. Carvalho, "Sustainable batch process retrofit design under uncertainty-An integrated methodology," Comput. Chem. Eng., (2016)

[7] O. Alshekhli, D. C. Y. Foo, C. L. Hii, and C. L. Law, "Process simulation and debottlenecking for an industrial cocoa manufacturing process," Food Bioprod. Process., 89, pp. 528-536, (2011)

[8] R. R. Tan et al., "An algebraic approach to identifying bottlenecks in linear process models of multifunctional energy systems," Theor. Found. Chem. Eng., 46, no. 6, pp. 642-650, 2012.

[9] N. Tahouni, R. Khoshchehreh, and M. H. Panjeshahi, "Debottlenecking of condensate stabilization unit in a gas refinery," Energy, 77, pp. 742-751, (2014)

[10] V. M. Enríquez-Gutiérrez, M. Jobson, L. M. Ochoa-Estopier, and R. Smith, "Retrofit of heat-integrated crude oil distillation columns," Chem. Eng. Res. Des., 99, pp. 185-198, (2015)

[11] H. Sugiyama et al., "Multiobjective Retrofitting Methodology for Manufacturing Processes of Active Pharmaceutical Ingredients Considering Environment, Health and Safety Risks," in Computer Aided Chemical Engineering, 38, pp. 79-84, (2016) 
[12] L. T. Biegler and P. Saderne, "A mixed integer flowsheet optimization strategy for process retrofits - the debottlenecking problem,", 13, no. 8, pp. 947-957, (1989)

[13] V. Andiappan, D. S. Ng, and R. R. Tan, "Design operability and retrofit analysis (DORA) framework for energy systems," Energy, (2017)

[14] Lindo Systems Inc., "LINGO," (2017) [Online]. Available: http://www.lindo.com/index.php/products/lingo-and-optimization-modeling. [Accessed: 22-Nov-2017]. 